\title{
Corticomuscular coherence in the acute and subacute phase after stroke
}

Larsen, Lisbeth Hoejkjaer; Zibrandtsen, Ivan Chrilles; Wienecke, Troels; Kjaer, Troels Wesenberg; Christensen, Mark Schram; Nielsen, Jens Bo; Langberg, Henning

Published in:

Clinical Neurophysiology

Link to article, DOI:

10.1016/j.clinph.2017.08.033

Publication date:

2017

Document Version

Peer reviewed version

Link back to DTU Orbit

Citation (APA):

Larsen, L. H., Zibrandtsen, I. C., Wienecke, T., Kjaer, T. W., Christensen, M. S., Nielsen, J. B., \& Langberg, H. (2017). Corticomuscular coherence in the acute and subacute phase after stroke. Clinical Neurophysiology, 128(11), 2217-2226. https://doi.org/10.1016/j.clinph.2017.08.033

\section{General rights}

Copyright and moral rights for the publications made accessible in the public portal are retained by the authors and/or other copyright owners and it is a condition of accessing publications that users recognise and abide by the legal requirements associated with these rights.

- Users may download and print one copy of any publication from the public portal for the purpose of private study or research.

- You may not further distribute the material or use it for any profit-making activity or commercial gain

- You may freely distribute the URL identifying the publication in the public portal 


\section{Accepted Manuscript}

Corticomuscular coherence in the acute and subacute phase after stroke

Lisbeth Hoejkjaer Larsen, Ivan Chrilles Zibrandtsen, Troels Wienecke, Troels Wesenberg Kjaer, Mark Schram Christensen, Jens Bo Nielsen, Henning Langberg

PII: S1388-2457(17)30960-4

DOI: https://doi.org/10.1016/j.clinph.2017.08.033

Reference: CLINPH 2008262

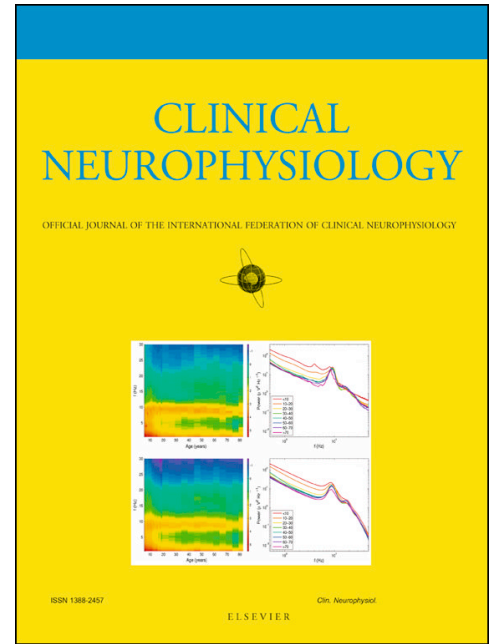

To appear in:

Clinical Neurophysiology

Accepted Date:

21 August 2017

Please cite this article as: Hoejkjaer Larsen, L., Chrilles Zibrandtsen, I., Wienecke, T., Wesenberg Kjaer, T., Schram Christensen, M., Bo Nielsen, J., Langberg, H., Corticomuscular coherence in the acute and subacute phase after stroke, Clinical Neurophysiology (2017), doi: https://doi.org/10.1016/j.clinph.2017.08.033

This is a PDF file of an unedited manuscript that has been accepted for publication. As a service to our customers we are providing this early version of the manuscript. The manuscript will undergo copyediting, typesetting, and review of the resulting proof before it is published in its final form. Please note that during the production process errors may be discovered which could affect the content, and all legal disclaimers that apply to the journal pertain. 


\section{Corticomuscular coherence in the acute and subacute phase after stroke}

Lisbeth Hoejkjaer Larsen, MSc ${ }^{a, b, *}$

Ivan Chrilles Zibrandtsen, $M D^{c}$

Troels Wienecke, $P h D^{c}$

Troels Wesenberg Kjaer, Professor ${ }^{c}$

Mark Schram Christensen, $P h D^{b, d}$

Jens Bo Nielsen, Professor ${ }^{b}$

Henning Langberg, Professor ${ }^{a}$

${ }^{a}$ CopenRehab, Department of Public Health, University of Copenhagen, 1014 Cph. K, Denmark

${ }^{b}$ Section for Integrative Neuroscience, Center for Neuroscience, University of Copenhagen, 2200 Cph. N, Denmark

${ }^{c}$ Department of Neurology, Zealand University Hospital, University of Copenhagen, 4000 Roskilde, Denmark

${ }^{d}$ DTU Compute, Department of Applied Mathematics and Computer Science, Technical University of Denmark, 2800

Kgs. Lyngby, Denmark

* Corresponding author:

Lisbeth Hoejkjaer Larsen,

Panum Institute, Blegdamsvej 3, 2200 Copenhagen N, Denmark

E-mail: lihl@sund.ku.dk 


\title{
Highlights
}

- Corticomuscular coherence (CMC) and intermuscular coherence (IMC) were reduced in acute and subacute stroke compared to healthy controls.

- $\quad \mathrm{CMC}$ was localized above the contralateral sensorimotor cortex in both patients and controls.

- Improvement of hand motor performance did not require changes in CMC or IMC.

\begin{abstract}
Objective: Stroke is one of the leading causes of physical disability due to damage of the motor cortex or the corticospinal tract. In the present study we set out to investigate the role of adaptations in the corticospinal pathway for motor recovery during the subacute phase after stroke.

Methods: We examined 19 patients with clinically diagnosed stroke and 18 controls. The patients had unilateral mild to moderate weakness of the hand. Each patient attended two sessions at approximately 3 days (acute) and 38 days post stroke (subacute). Task-related changes in the communication between motor cortex and muscles were evaluated from coupling in the frequency domain between EEG and EMG during movement of the paretic hand.

Results: Corticomuscular coherence (CMC) and intermuscular coherence (IMC) were reduced in patients as compared to controls. Paretic hand motor performance improved within 4-6 weeks after stroke, but no change was observed in CMC or IMC.

Conclusions: CMC and IMC were reduced in patients in the early phase after stroke. However, changes in coherence do not appear to be an efficient marker for early recovery of hand function following stroke.

Significance: This is the first study to demonstrate sustained reduced coherence in acute and subacute stroke.
\end{abstract}

Keywords: Ischemic stroke; Subacute phase; Hemiparesis; Motor recovery; Corticomuscular coherence; Intermuscular coherence. 


\section{Abbreviations}

ADP, adductor pollicis; APB, abductor pollicis brevis; CMC, corticomuscular coherence; CST, corticospinal tract; EEG, electroencephalographic; EMG, electromyographic; FDI, first dorsal interosseous; IMC, intermuscular coherence; M1, primary motor cortex; MVC, maximal voluntary contraction. 


\section{Introduction}

Stroke results from critically reduced blood flow to the brain tissue due to bleeding or obstruction of arteries. Globally, stroke remains a major cause of disability despite advances in preventive treatment and in acute management (Hankey, 2017). The most common impairment caused by stroke is motor disability affecting approximately $80 \%$ of the patients, most frequently seen as hemiparesis (Langhorne et al. , 2009). Spontaneous recovery may occur in the following weeks and months after stroke and can be facilitated through rehabilitation involving exercise (Maulden et al. , 2005). Despite of this, upper limb motor impairments are often persistent and disabling (Lai et al. , 2002) and no rehabilitation program has been proven superior to other programs (Pollock et al. , 2014). Strategies aiming at enhancing rehabilitation programs require a greater understanding of the mechanisms of recovery. In the present study we set out to investigate the role of adaptations in the corticospinal tract (CST) for motor recovery of the affected hand during the subacute phase after stroke.

Studies performed in monkeys have demonstrated severe deficits in precise finger movements following selective lesion to the CST (Lawrence et al. , 1968) and diffusion-tensor imaging studies have consistently shown a relation between damaged CST fibres and motor deficits (Stinear et al. , 2007, Schulz et al. ,2012). In primates most of the neurons in the CST originate in the primary motor cortex (M1) and a subset of these makes direct, cortico-motoneuronal connections with spinal motoneurons especially towards distal finger muscles (Porter et al. , 1993). Evidence suggest that these direct connections play a key role in fractionated finger movements, which are important for manipulation of small objects (Lemon et al. , 2004). It is believed that the direct connections work in parallel with the more indirect connections by adding the final spatiotemporal excitation patterns in order to produce appropriate levels of motoneuronal recruitment and discharge (Lemon et al. , 2004). Disconnection of direct and indirect connections in the CST is assumed to be a major cause of impaired hand and finger motor function after stroke (Lemon, 2008).

Estimates of task-related corticospinal connections can be noninvasively determined during finger movements from coherence analysis in human subjects. This measurement allows a statistical analysis to be performed to characterize the functional coupling in the frequency domain (coherence) between cortical oscillatory activity (measured by EEG) and motor activity (measured by EMG) during a task (Halliday et al. , 1995). I addition, coherence analysis of surface EMG within and between muscles provides a complementary means of measuring and detecting changes 
in the CST (Grosse et al. , 2002). Previously cross-sectional studies have demonstrated that corticomuscular coherence (CMC) is reduced in the chronic phase after stroke (Mima et al. , 2001, Braun et al. , 2007, Fang et al. , 2009, Rossiter et al. , 2013) and furthermore that CMC can increase in the chronic phase after training (Belardinelli et al. , 2017), with peripheral electrical stimulation (Lai et al. , 2016) and with time (von Carlowitz-Ghori et al. , 2014). However the adaptations in the CST during the first 4-6 weeks post-stroke, where the most dramatic improvements occur, have not been investigated. We hypothesized that $\mathrm{CMC}$ will be reduced in stroke patients and will increase in parallel to the stroke patient's improvement in functional performance during early recovery.

\section{Materials and methods}

\subsection{Participants}

We examined 19 patients (mean age 61 years, range 31-86 years, 2 females, 1 left-handed) with clinically diagnosed stroke and 18 control participants with no history of stroke (mean age 65 years, range 33-88 years, 5 females, 0 left-handed). The stroke patients had unilateral mild to moderate motor weakness of the hand (7 dominant hand affected). We excluded patients with hemorrhagic stroke, those unable to perform the pinch grip task and those with language/cognitive deficits sufficient to impair cooperation in the experiment. Motor strength of the affected hand was graded according to the modified MRC scale (Medical Research Council, 1986). A full written consent was obtained from all participants in accordance with the Declaration of Helsinki. The study was approved by the Ethics Committee of Region Zealand (protocol-number: SJ-459).

\subsection{Experimental design}

Patients attended two sessions at approximately 3 days (Time 1; T1) and 38 days (Time 2; T2) post stroke. Hand preference before stroke was determined by handedness questionnaire (Oldfield, 1971) and cognitive ability and neglect were evaluated based on the mini mental state examination (Folstein et al. , 1975) and a general clinical assessment. During the experiment the patients were seated in an adjustable chair with their forearms resting comfortably on a table. Patients were scored on the Grooved Pegboard Test (Strauss, 2006) before they were instructed to control a lever placed in front of them with their affected thumb and index finger. Visual feedback of the force exerted was provided on a computer screen and the patients completed 3 maximal pinch grip 
contractions (MVC). A dynamic pinch task was then performed with the affected hand (Fig. 1A). Patients were instructed to track a moving target (a ramp) as accurately as possible, by applying force to the levers (Fig. 1B). A cursor moved automatically across the screen from left to right at a constant velocity and force applied to the levers moved the cursor upward. The force level of the ramp plateau (y-axis) was set to an individual level (10\%MVC) lasting $3 \mathrm{~s}$ followed by a rest interval of 3-5 s. Patients performed $3 \times 50$ trials with $60 \mathrm{~s}$ of rest in between. Before recording, patients were acquainted with the setup and trained to control the lever. The force was measured with a load cell (UU2-K30, Dacell, Korea) and the trials were recorded by Signal software (CED, Cambridge, UK) and stored for later analysis. Control participants attended one session and they used either left or right hand in order to match the side of the affected hand in the stroke group.

\subsection{Electrophysiological measurements}

Data recorded included EEG activity from 64 electrodes and EMG activity from the affected hand (ActiveTwo, BioSemi, Amsterdam, The Netherlands) using acquisition software ActiView (version 6.05). Active EEG electrodes were mounted in a headcap (Headcap BioSemi, The Netherlands) with an electrode configuration complying with the 10-10 system. Three pairs of bipolar active EMG surface electrodes were placed on the affected (active) hand over first dorsal interosseous muscle (FDI), adductor pollicis (ADP) and abductor pollicis brevis (APB) muscles (interelectrode distance, $15 \mathrm{~mm}$ ). EMG was recorded as part of the EEG dataset and so had the same preprocessing parameters. In BioSemi the ground electrode is formed by the Common Mode Sense active electrode and the Driven Right Leg passive electrode during acquisition. Offset values were below \pm 25 microV and recordings were set to AC and sampled at $2048 \mathrm{~Hz}$.

\subsection{Statistical analysis}

Data analyses were performed using Matlab R2015a (MathWorks, MA, USA), with the toolbox EEGLAB v13.4.4b (Swartz Center for Computational Neuroscience; http://sccn.ucsd.edu/eeglab/) and the toolbox Statistical Parametric Mapping (SPM12). All files were imported to EEGLAB and a $5 \mathrm{~Hz}$ high-pass filter were applied. This high-pass filter was applied in order to eliminate movement artifacts below $5 \mathrm{~Hz}$. Higher cutoff frequencies have recently been shown to result in a decrease of the reliability and agreement of the coherence variables (van Asseldonk et al. , 2014). Channels with significant drift or excessive $50 \mathrm{~Hz}$ noise were removed using visual inspection of the EEG signals before data was re-referenced to average reference. The analysis was based on the 
steady contraction period during the ramp plateau, in which the strongest coherent activity in the beta band has been shown before (Kilner et al. , 1999). The interval between 0.85 and $2.85 \mathrm{~s}$ after ramp onset showed a stable force production across participants and was used for further analysis of CMC and intermuscular coherence (IMC). The data were visually inspected and trials were discarded if a force reaction was clearly missing. Because coherence strength may relate to the number of trials across participants an equal number of trials were included for all participants based on the lowest number of accepted trials in one participant (142 trials). EEG channels and rectified EMG signals (Halliday et al. , 2010) were normalized to have unit variance (Halliday et al. , 2000). Estimates of the power spectra in the steady interval were constructed from averaging periodograms across all trials generating $f_{x x}(\lambda)$ and $f_{y y}(\lambda)$, that represent the Fourier transforms of processes $\mathrm{x}$, and $\mathrm{y}$, at frequency $\lambda$. The cross spectrum between $\mathrm{x}$ and $\mathrm{y}, f_{x y}(\lambda)$ was estimated in a similar manner. The correlation between EEG and EMG (or between EMG-EMG) signals at a given frequency $\lambda$ was then assessed through the coherence function:

$$
\left|R_{x y}(\lambda)\right|^{2}=\frac{\left|f_{x y}(\lambda)\right|^{2}}{f_{x x}(\lambda) f_{y y}(\lambda)}
$$

Coherence estimates provides a measure of linear association on a scale from 0 to 1 . In addition, the cumulant density function was used to characterize the signals' correlation in an unbounded timedomain (Halliday et al. , 1995). In the present data, CMC estimates provide a measure of the fraction of the activity in the three surface $\mathrm{EMG}$ signals $\left(\mathrm{EMG}_{\mathrm{FDI}}, \mathrm{EMG}_{\mathrm{APB}}, \mathrm{EMG}_{\mathrm{ADP}}\right.$, ) at any given frequency that can be predicted by the activity in any of the 64 EEG signals measured at the cortex while IMC estimates provides a measure of the fraction of activity in $\mathrm{EMG}_{\mathrm{FDI}}$ signal that can be predicted by the activity in $\mathrm{EMG}_{\mathrm{APP}}$ or $\mathrm{EMG}_{\mathrm{ADP}}$ signal. In this way, coherence estimates quantify the strength of the coupling between cortex and the three muscles (CMC) and estimates the common input to the muscles (IMC). Scalp plots were generated with the CMC values in the beta band $(15-30 \mathrm{~Hz})$ from each scalp electrode towards each muscle. Data collection acquired during right hand use was flipped in the sagittal plane, so that the right hemisphere was contralateral to the moving hand in all participants. The individually scalp plots were checked for the presence of widespread coherence before averaging of participants in one scalp plot. Further statistical testing was performed on the cortical electrode with the most coherent activity (presumably above the contralateral sensorimotor cortex) toward the three hand muscles based on the average scalp plots.

Unfortunately the small distance between locations of measurements caused a widespread crosstalk between the EMG signals in 5 of the patients evaluated from the phase- 
frequency relationship (Grosse et al. , 2002) and coherence estimates beyond relevant frequencies. According to Farina et al. (2014) there are currently no analytical procedures that can eliminate cross talk in a recorded EMG signal (Farina et al. ,2014) therefore 5 patients were excluded for the analysis of $\mathrm{EMG}_{\mathrm{FDI}}-\mathrm{EMG}_{\mathrm{ADP}}$ coherence and 4 patients for the $\mathrm{EMG}_{\mathrm{FDI}}-\mathrm{EMG}_{\mathrm{APB}}$ coherence.

In order to summarize coherence and cumulant density across participants, the individual estimates were pooled providing a single time or frequency domain measure (Amjad et al. , 1997). Statistical difference of coherence was calculated using the Chi-Squared $\chi^{2}$ extended difference of coherence test (Amjad et al. , 1997). The $\chi^{2}$ difference test provides a metric of the coherence difference at each frequency where significance is assessed through inclusion of an upper 95\% confidence limit. In this study, estimates of pooled coherence were used to summarize the correlation structure in patients at two different time points (T1 and T2) after stroke and in control participants. To further quantify and identify the spread of individual coherence, the logarithmic value of the sum of coherence in the alpha band $(5-15 \mathrm{~Hz})$, the beta band $(15-30 \mathrm{~Hz})$ and the gamma band $(30-50 \mathrm{~Hz})$ were calculated and compared between controls and patients at $\mathrm{T} 1$ and $\mathrm{T} 2$ with respectively an unpaired- and paired-sample t-test.

The performance in the dynamic pinch task was measured as the root mean square (RMS) value of the error distance between the patient's torque signal and the displayed ramp load in the steady interval of the ramp plateau. In order to investigate the relation between performance and coherence, both the peak and area under the curve in the beta band were used. Non-normally distributed data was log-transformed and a two-tailed Pearson's correlation analyses were performed to test the relation between behavioral measurements and amount of coherence in patients and in control participants. A two-sampled t-test was use to investigate differences in behavioral measurements between patients and control participants and a paired-sampled t-test was used to investigate differences from $\mathrm{T} 1$ to $\mathrm{T} 2$. Statistical analyses were performed in Matlab. Results are presented in means \pm SD in text and as means \pm SE in figures.

\section{Results}

Nineteen patients were recruited for this study. Four patients were excluded for statistical analysis: One due to an error in hardware settings, one who could not co-operate to the dynamic pinch task and two patients had a medical history of previous stroke. Baseline characteristics for the 15 remaining patients are shown in Table 1. Two patients cancelled their second recording day due to 
psychological and physiological tiredness caused by the stroke.

From T1 to T2 patients improved their MVC from $34 \pm 14 \mathrm{~N}$ to $40 \pm 14 \mathrm{~N}(t=-2.25, p$ $=0.04)$, their pegboard score from $8 \pm 3 \mathrm{pegs} / 30 \mathrm{~s}$ to $13 \pm 4 \mathrm{pegs} / 30 \mathrm{~s}(t=-5.36, p<0.001)$ and their performance in the dynamic pinch task from $4 \pm 2$ RMS to $3 \pm 1$ RMS $(t=4.02, p<0.01)$ (Fig. 2). Compared to controls the patients' MVC was lower at T1 $(t=-2, p=0.05)$ but not at T2 $(t=-0.59$, $p=0.56)$ (Fig. 2A). The pegboard score was lower for patients than controls at both $\mathrm{T} 1(t=-8.44, p$ $<0.001)$ and T2 $(t=-2.9, p<0.01)$ (Fig. 2B) while performance in the dynamic pinch task was lower for patients at T1 compared to controls $(t=2.87, p<0.01)$ but not at T2 $(t=-0.1, p=0.92)$ (Fig. 2C).

In order to investigate fatigue in each session EMG signals from the first 25 trials was compared with the last 25 trials in FDI, APB and ADP separately. No increase in the amplitude and no decrease of the median power frequency were observed from the beginning to the end either in patients (T1 or T2) or in controls in any of the three muscles. In addition we observed an increase of performance from the first 25 trials to the last 25 trials in both patients at T1, T2 and in controls with no difference of the improvement rate between groups.

Figure 3 shows an example of the different components analyzed for each person before pooling the data calculated from the $2 \mathrm{~s}$ hold phase in the dynamic pinch task and illustrated with data from one patient and one control participant. The power spectrum is shown for the EEG activity measured from the contralateral sensorimotor cortex (Fig. 3A). A peak around $10 \mathrm{~Hz}$ is observed for the patient whereas a peak around $20 \mathrm{~Hz}$ is observed for the control participant. The $\mathrm{EMG}_{\mathrm{FDI}}$ power spectrum shows a peak around 8-12 Hz for the patient and a peak around $13-15 \mathrm{~Hz}$ for the control participant (Fig. 3B). Figure 3C shows that the coherence estimate for the control participant was enhanced at the frequencies $10-25 \mathrm{~Hz}$, whereas no enhanced coherence can be observed for the patient. The correlation in the time domain is estimated with the cumulant density function and shows a more pronounced peak for the control participant compared to the patient (Fig. 3D). The pooled EEG and EMG power spectra as well as the pooled cumulant density estimate were in line with the results from the individual patient/control participant (Fig. 3A-B, D). Thus the EEG power spectra data peaked around 10 and $20 \mathrm{~Hz}$ where $10 \mathrm{~Hz}$ was more pronounced for the patients at both $\mathrm{T} 1$ and $\mathrm{T} 2$ and $20 \mathrm{~Hz}$ was more pronounced for the control group. The power spectra for EMG peaked around $12 \mathrm{~Hz}$ for patients with no change between T1 and T2 and around $15 \mathrm{~Hz}$ for control participants while the cumulant density showed a more pronounced peak for the control participant compared to the patient at both T1 and T2 (data not shown). 
Figure 4A-C shows pooled coherence data between the contralateral sensorimotor cortex and the three finger muscles from 15 patients at T1, 13 patients at T2 and 18 control participants. Significant coherence was observed at 10-25 Hz for patients in EEG-EMG FDI $_{\text {(Fig. 4A) }}$ and EEG-EMG $\mathrm{ADP}_{\mathrm{AP}}$ (Fig. 4C) at both $\mathrm{T} 1$ and $\mathrm{T} 2$ and in EEG-EMG $\mathrm{APB}_{\mathrm{AP}}$ at T2 (Fig. 4B). Control participants showed significant coherence at $15-25 \mathrm{~Hz}$ in all three muscles (Fig. 4A-C). Calculated from the $\chi^{2}$ extended test for differences significantly higher coherence was observed at $17-25 \mathrm{~Hz}$ for controls participants compared to patients in all muscles while no convincing difference was observed in CMC between $\mathrm{T} 1$ and $\mathrm{T} 2$ in any of the three muscles (Fig. 4D-F). Significant coherence was observed in a wide frequency range for both $\mathrm{EMG}_{\mathrm{FDI}}-\mathrm{EMG}_{\mathrm{APB}}$ and $\mathrm{EMG}_{\mathrm{FDI}}{ }^{-}$ $\mathrm{EMG}_{\mathrm{ADP}}$ in both patients and controls (Fig. 4G-H). $\chi^{2}$ extended test for differences showed significantly higher 5-25 Hz coherence for $\mathrm{EMG}_{\mathrm{FDI}}-\mathrm{EMG}_{\mathrm{APB}}$ (Fig $4 \mathrm{I}$ ) and 8-33 Hz coherence for $\mathrm{EMG}_{\mathrm{FDI}}-\mathrm{EMG}_{\mathrm{ADP}}(\mathrm{Fig} 4 \mathrm{~J})$ in controls as compared to patients. No significant difference was observed in IMC between patients at T1 and T2 (Fig.4I-J). In addition, we observed that the two excluded patients that have previously suffered from a stroke showed higher 5-25 Hz IMC but no difference in CMC compared to the rest of the patients (data not shown).

The individual amount of CMC and IMC calculated, as the area under the curve is shown for patients at T1 and T2 for the alpha band (Fig. 5A-E) and for the beta band (Fig. 5F-J). This approach of quantifying CMC and IMC showed no difference from $\mathrm{T} 1$ and $\mathrm{T} 2$ in either frequency bands. Reduced EEG-EMG $\mathrm{APB}_{\mathrm{AB}}$ coherence was found in patients at $\mathrm{T} 1$ compared to controls in the alpha band $(t=-2.08, p=0.05)$ and in the beta band $(t=-3.04, p<0.01)$, but not in the alpha band or beta band for EEG-EMG $\mathrm{FDI}_{(}(t=-0.66, p=0.52 \& t=-1.93, p=0.06)$ or EEG$\mathrm{EMG}_{\mathrm{ADP}}(t=-0.72, p=0.48 \& t=-1.71, p=0.1)$. Furthermore, reduced IMC was found in patients at $\mathrm{T} 1$ compared to controls in the beta band for $\mathrm{EMG}_{\mathrm{FDI}}-\mathrm{EMG}_{\mathrm{APB}}(t=-2.09, p=0.05)$ and $\mathrm{EMG}_{\mathrm{FDI}^{-}}$ $\operatorname{EMG}_{\mathrm{ADP}}(t=-3.09, p<0.01)$ but not in the alpha band $(t=-1.44, p=0.16 \& t=-1.46, p=0.16)$.

Coherence in the gamma band was also calculated but is not shown due to a very small amount of coherence within this frequency band (see Fig. 4) with no change between patients at T1 and T2 or between controls and patients at $\mathrm{T} 1$.

Figure 6 shows average scalp plots of CMC between EEG channels and MMG $_{\mathrm{FDI}}$ in the beta band. The most coherent activity was found above the contralateral sensorimotor cortex at $\mathrm{C} 3 / \mathrm{C} 4$ and an examination of the individual scalp plots did not reveal any clear pattern of widespread CMC activity. Thus the C3/C4 electrode was used for analysis of coherence estimates. The average scalp plots of $C M C$ from EEG-EMG ${ }_{\mathrm{APB}}$ and EEG-EMG $\mathrm{ADP}_{\mathrm{AP}}$ showed similar coherent 
activity with the highest correlation towards the electrode above the contralateral sensorimotor cortex (data not shown).

No relation was observed at T1, T2 or in the control participants between performance in the dynamic pinch task and EEG-EMG ${ }_{\mathrm{FDI}}$ coherence quantified as peak values or area under the curve in the beta band. We also found no correlation between CMC and MVC or between CMC and pegboard scores at T1, T2 or in control participant. Given that inter-subject variation in coherence can be high even in healthy individuals (Jaiser et al. , 2016), we also analyzed the correlation between changes in $\mathrm{CMC}$ and changes in performance score but this also revealed no correlations. The same pattern was observed for EEG-EMG ${ }_{\mathrm{APB}}, \mathrm{EEG}-\mathrm{EMG}_{\mathrm{ADP}}, \mathrm{EMG}_{\mathrm{FDI}}-\mathrm{EMG}_{\mathrm{APB}}$ and $\mathrm{EMG}_{\mathrm{FDI}}{ }^{-}$ $\mathrm{EMG}_{\mathrm{ADP}}$. We also did not observe any relation between age and coherence in patients or control participants.

\section{Discussion}

In this study, simultaneous EEG and EMG recordings were obtained from cortex and affected finger muscles during an isometric pinch grip to investigate the task-related coupling in the early phase after stroke. The results provide evidence that both CMC and IMC are reduced in the acute phase after stroke with no significant change within the following 4-6 weeks despite improved behavioral performance in the dynamic pinch task, MVC and pegboard score.

$\mathrm{CMC}$ is a marker of the corticospinal pathway based on the functional coupling between oscillatory signals from the brain and active muscles (Conway et al. , 1995). A significant coupling between the two signals is usually observed within the beta band during an isometric pinch grip (Kilner et al., 1999). In line with previous studies we observed that CMC was not only reduced in this frequency range, but also occurred at somewhat lower frequencies after stroke compared to healthy age-matched controls (Mima et al. , 2001, von Carlowitz-Ghori et al. , 2014). It has been suggested that decreased CMC and slowing of CMC frequencies are related to aging (Kamp et al. , 2013). However, this is unlikely to explain the findings in the present study, since stroke and control participants were at the same age. We also did not find any correlation between age and CMC. It seems more likely that the lower frequencies and the reduction of CMC are both related to changes in the oscillatory properties of the network responsible for generating CMC following stroke. The partial disconnection of corticospinal neurons is likely to influence the excitability and discharge properties of both projection neurons and local inhibitory and excitatory interneurons in 
the motor cortex (Hansen et al. , 2004). The properties of spinal motor neurons and the muscle fibres they innervate have also been shown to change following damage to the CNS (Thomas et al. , 2002) and changes in the sensory feedback mechanisms may also play an important role in the 15$30 \mathrm{~Hz}$ CMC (Witham et al. , 2011). The general clinical exam revealed a small sensory loss in 6 patients. This may have contributed to the reduced amount of CMC.

IMC in the beta band is related to CMC (Kilner et al. , 1999) and appears to reflect the common oscillatory drive to the motor units from branches of corticospinal tract fibres. Nevertheless, additional oscillatory presynaptic drives to spinal motoneurons other than those of cortical origin also contribute to IMC (Grosse et al. , 2002), which may explain why the amount of IMC is more pronounced than CMC in both patient and controls. Interesting, in data from two patients previously suffering from a stroke higher $5-25 \mathrm{~Hz}$ IMC than the rest of the patients was observed suggesting that recovery from the first stroke have involved an increase of subcortical plasticity for the two patients.

A frequent finding in PET and fMRI studies is that patients with stroke show more task-related brain activation in both the affected and the unaffected hemisphere (Rehme et al. , 2012). The topographic distribution of significant CMC on the contralateral (affected) hemisphere was however similar in the present study to the distribution in control participants although the amount of coherence was smaller. This is in line with previous CMC studies that did not observe a shift towards the ipsilateral side (Mima et al. , 2001, Braun et al. , 2007, Fang et al. , 2009, von Carlowitz-Ghori et al. , 2014, Lai et al. , 2016). Yet, two recent CMC studies found coherent activity between affected muscles and primary and secondary motor cortices in both the affected and unaffected hemisphere (Rossiter et al. , 2013, Belardinelli et al. , 2017). Of note, findings from TMS studies has previous suggested a contralesional shift in balance of functionally relevant activity with greater impairment (Johansen-Berg et al. , 2002, Fridman et al. , 2004) which may explain the bilateral CMC observed in severely impaired patients in the study by Belardinelli et al. (2017). However Rossiter et al. (2013) included patients of various impairments and did not find any correlation between impairment and location of CMC (Rossiter et al. , 2013). It seems natural to assume that pre-existing ipsilateral corticospinal connections compensate for damage to the crossed pathways, however evidence for the control of the hand movements via ipsilateral corticospinal connections is weak in primates and humans (Werhahn et al. , 2003, Soteropoulos et al. , 2011, Zaaimi et al. , 2012). Alternatively task-related changes in ipsilateral CMC may be mediated by bilateral cortico-reticulospinal connections (Soteropoulos et al. , 2012, Zaaimi et al. , 
2012, Foysal et al. , 2016). Further investigation is needed for a more complete understanding of the relationship between functional recovery and widespread CMC in humans.

To our knowledge adaptations in CMC have not previously been investigated during early recovery following stroke. Surprisingly, despite clear improvements in performance we did not observe any significant changes in CMC between the contralateral sensorimotor cortex and affected muscles. This is in contrast to the study by von Carlowitz-Ghori et al. (2014) who found an increase in the amount of CMC from the acute to the early chronic stage ( $\sim$ months post stroke) in 7 patients following stroke (von Carlowitz-Ghori et al. , 2014) and to Belardinelli et al. (2017) who observed an increase in CMC after a four-week rehabilitative intervention in severely impaired chronic stroke patients. Belardinelli et al. (2017) report that behavioral improvements were observed in parallel with an increase in CMC but the motor gains and the pattern of CMC changes were not correlated. In another study by Braun et al. (2007) a relation between behavioral performance and CMC was found in stroke patients in the chronic phase, but not in healthy participants concluding that the correlation between motor performance and CMC was specific for patients with stroke (Braun et al. , 2007). However, a similar relation between CMC and performance in patients with stroke in the chronic phase has not been found in other studies (Graziadio et al. , 2012, Rossiter et al., 2013, Belardinelli et al. , 2017). Different methods, e.g. synergistic activation verses individuated finger control (Reyes et al. ,2017) and different ways of quantifying CMC (e.g. peak, area under the curve) probably explain these discrepancies. In an attempt to address this we tested correlations between all included behavioral measurements and coherence quantified as both peak values and area under the curve in the beta band, but found no significant correlations. Thus, regardless of different approaches it appears that improved performance can occur without a clear correlation to CMC or IMC suggesting that coherence is not an efficient marker for early recovery of hand function following stroke.

A recent study from 2017 showed that the critical window of spontaneous recovery occur within the first 5 weeks after stroke (Cortes et al. , 2017). In addition finger strength seems to have a faster improvement rate compared to independent control of fingers after stroke (Sunderland et al. , 1989, Xu et al. , 2017). This is in line with our study where we observed an increase in all performance measurements in patients from $\mathrm{T} 1$ to $\mathrm{T} 2$, but a persistent reduced pegboard score in patients compared to controls. The pegboard task requires independent control of fingers, whereas the pinch grip strength and the dynamic pinch task involve a combination of strength and precision control of individual fingers ( $\mathrm{Xu}$ et al. , 2015). It may therefore be that the changes in performance 
that we observed are primarily related to recovery of muscle strength rather than improved muscle coordination. This would be consistent with the increase in MVC and it might also provide a possible explanation why we observed no change in CMC from $\mathrm{T} 1$ to $\mathrm{T} 2$, since changes in $\mathrm{CMC}$ have mainly been observed in other studies in relation to improvements in coordination (Larsen et al. , 2016).

It could also be speculated that reorganization in mild impaired patients rely more on cortico-cortical adaptations and interhemispheric connectivity rather than the oscillatory properties of the sensory-motor network involving the corticospinal pathways. A study combining TMS, MRI and analyses of connectivity investigated the role of CST damage, cortical excitability and motor network effective connectivity for recovery of hand function in chronic stroke patients with mild to moderate unilateral hand motor deficits (Volz et al. , 2015). The authors found that persistent impairments of hand motor function after stroke are not only reflected by the amount of CST damage. Rather, changes in ipsilesional (affected) M1 excitability and interhemispheric connectivity beyond the structural damage seem to contribute to motor function. Furthermore, a recent diffusion-tensor imaging study demonstrated that in chronic stroke patients with relatively less motor impairment motor recovery correlated with structural integrity in the corpus callosum but not the CST, while in patients with relatively greater motor impairment, motor recovery correlated with structural integrity in the CST but not the corpus callosum (Stewart et al. , 2017).

Finally it has been suggested that CMC primarily reflect transient signal bindings and working memory-related activities, which would mean that the amount of CMC is highly influenced by attentional demands and the timing of measurement in relation to e.g. motor training (Kristeva-Feige et al., 2002, Perez et al. , 2006). Studies investigating CMC following a single bout of training in healthy participants have demonstrated that CMC is enhanced shortly after training and return to baseline within minutes despite maintained motor performance abilities (Perez et al. , 2006, Geertsen et al. , 2013, Larsen et al. , 2016). Hence, we speculate that CMC may contribute to recovery by helping preserve and strengthen newly formed projections in a time-dependent manner.

Some limitations need to be acknowledged. All patients were CT-scanned, but only in some of them was an additional MRI scanning performed to more precisely localize small lesions. However, Rossiter et al. (2013) found no relation between CMC and lesion location suggesting that functional impairment rather than lesion location seems to be a feasible selection criterion (Rossiter et al. , 2013). In the pooled coherence analyses the controls showed a significantly higher CMC and IMC than patients in frequencies of respectively $17-25 \mathrm{~Hz}$ (fig 4D-F) and 5-33 Hz (Fig. 4I-J). IMC 
and $\mathrm{CMC}$ for $\mathrm{EEG}-\mathrm{EMG}_{\mathrm{APB}}$ quantified, as area under the curve showed similar results while the difference for $\mathrm{EEG}-\mathrm{EMG}_{\mathrm{FDI}}$ and $\mathrm{EEG}-\mathrm{EMG}_{\mathrm{ADP}}$ was less convincing. The variability in $\mathrm{CMC}$ is high even in the controls, which may be part of the reason for this.

Increased $\mathrm{CMC}$ has previously been observed in healthy participants during fatiguing contractions (Tecchio et al. , 2006). In the present study, we cannot exclude that fatigue influenced the amount of coherence measured in both control participants and stroke patients. However, we found no increase in EMG amplitude or decrease of EMG median power frequency, which are usually good indicators of fatigue (Kallenberg et al. , 2007), during the trials in either patients or controls. In addition, performance generally improved during the trials, which is also unlikely if fatigue had been a significant problem. We therefore find it unlikely that fatigue influenced the measurements of CMC or IMC in either group.

Finally we cannot exclude that a change in strategy between involved muscles may mask the role of adaptation in the CST and that other joints and muscles than the 3 finger muscles we estimated coherence from, have been involved in the optimization of task performance. In addition, surface EMG may be limited by volume conduction between muscles, which will also mask the result.

\section{Conclusion}

To our knowledge this is the first study to investigate CMC and IMC during the early recovery phase after stroke. The distribution of significant CMC above the contralateral (ipsilesional) sensorimotor cortex was similar to the distribution of control participants but the amount of both CMC and IMC was persistently reduced and CMC occurred at somewhat lower frequencies after stroke. No significant correlation was found between the amount of coherence and the level of functional recovery. Overall these results demonstrate a sustained reduced CMC and IMC in patients during the subacute phase after stroke where recovery of hand function does not require adaptations in coherence.

\section{Acknowledgements}

The study was supported by the research program "Physical activity and nutrition for improvement of health" funded by the University of Copenhagen Excellence Programme for Interdisciplinary Research. 


\section{Conflict of Interest Statement}

None of the authors have potential conflicts of interest to be disclosed. 


\section{References}

Amjad AM, Halliday DM, Rosenberg JR, Conway BA. An extended difference of coherence test for comparing and combining several independent coherence estimates: theory and application to the study of motor units and physiological tremor. J Neurosci Methods. 1997;73:69-79. Belardinelli P, Laer L, Ortiz E, Braun C, Gharabaghi A. Plasticity of premotor cortico-muscular coherence in severely impaired stroke patients with hand paralysis. Neuroimage Clin. 2017;14:72633.

Braun C, Staudt M, Schmitt C, Preissl H, Birbaumer N, Gerloff C. Crossed cortico-spinal motor control after capsular stroke. Eur J Neurosci. 2007;25:2935-45.

Conway BA, Halliday DM, Farmer SF, Shahani U, Maas P, Weir AI, et al. Synchronization between motor cortex and spinal motoneuronal pool during the performance of a maintained motor task in man. J Physiol. 1995;489 ( Pt 3):917-24.

Cortes JC, Goldsmith J, Harran MD, Xu J, Kim N, Schambra HM, et al. A Short and Distinct Time Window for Recovery of Arm Motor Control Early After Stroke Revealed With a Global Measure of Trajectory Kinematics. Neurorehabil Neural Repair. 2017;31:552-60.

Fang Y, Daly JJ, Sun J, Hvorat K, Fredrickson E, Pundik S, et al. Functional corticomuscular connection during reaching is weakened following stroke. Clin Neurophysiol. 2009;120:994-1002. Farina D, Merletti R, Enoka RM. The extraction of neural strategies from the surface EMG: an update. J Appl Physiol (1985). 2014;117:1215-30.

Folstein MF, Folstein SE, McHugh PR. "Mini-mental state". A practical method for grading the cognitive state of patients for the clinician. J Psychiatr Res. 1975;12:189-98.

Foysal KM, de Carvalho F, Baker SN. Spike Timing-Dependent Plasticity in the Long-Latency Stretch Reflex Following Paired Stimulation from a Wearable Electronic Device. J Neurosci. 2016;36:10823-30.

Fridman EA, Hanakawa T, Chung M, Hummel F, Leiguarda RC, Cohen LG. Reorganization of the human ipsilesional premotor cortex after stroke. Brain. 2004;127:747-58.

Geertsen SS, Kjaer M, Pedersen KK, Petersen TH, Perez MA, Nielsen JB. Central common drive to antagonistic ankle muscles in relation to short-term cocontraction training in nondancers and professional ballet dancers. J Appl Physiol (1985). 2013;115:1075-81.

Graziadio S, Tomasevic L, Assenza G, Tecchio F, Eyre JA. The myth of the 'unaffected' side after unilateral stroke: is reorganisation of the non-infarcted corticospinal system to re-establish balance the price for recovery? Exp Neurol. 2012;238:168-75. 
Grosse P, Cassidy MJ, Brown P. EEG-EMG, MEG-EMG and EMG-EMG frequency analysis: physiological principles and clinical applications. Clin Neurophysiol. 2002;113:1523-31.

Halliday DM, Farmer SF. On the need for rectification of surface EMG. J Neurophysiol. 2010;103:3547; author reply 8-9.

Halliday DM, Rosenberg JR. On the application, estimation and interpretation of coherence and pooled coherence. J Neurosci Methods. 2000;100:173-4.

Halliday DM, Rosenberg JR, Amjad AM, Breeze P, Conway BA, Farmer SF. A framework for the analysis of mixed time series/point process data--theory and application to the study of physiological tremor, single motor unit discharges and electromyograms. Prog Biophys Mol Biol. 1995;64:237-78.

Hankey GJ. Stroke. The Lancet. 2017;389:641-54.

Hansen NL, Nielsen JB. The effect of transcranial magnetic stimulation and peripheral nerve stimulation on corticomuscular coherence in humans. J Physiol. 2004;561:295-306.

Jaiser SR, Baker MR, Baker SN. Intermuscular Coherence in Normal Adults: Variability and Changes with Age. PLoS One. 2016;11:e0149029.

Johansen-Berg H, Rushworth MF, Bogdanovic MD, Kischka U, Wimalaratna S, Matthews PM. The role of ipsilateral premotor cortex in hand movement after stroke. Proc Natl Acad Sci U S A. 2002;99:14518-23.

Kallenberg LA, Schulte E, Disselhorst-Klug C, Hermens HJ. Myoelectric manifestations of fatigue at low contraction levels in subjects with and without chronic pain. J Electromyogr Kinesiol. 2007;17:264-74.

Kamp D, Krause V, Butz M, Schnitzler A, Pollok B. Changes of cortico-muscular coherence: an early marker of healthy aging? Age (Dordr). 2013;35:49-58.

Kilner JM, Baker SN, Salenius S, Jousmaki V, Hari R, Lemon RN. Task-dependent modulation of 15-30 Hz coherence between rectified EMGs from human hand and forearm muscles. J Physiol. 1999;516 ( Pt 2):559-70.

Kristeva-Feige R, Fritsch C, Timmer J, Lucking CH. Effects of attention and precision of exerted force on beta range EEG-EMG synchronization during a maintained motor contraction task. Clin Neurophysiol. 2002;113:124-31.

Lai MI, Pan LL, Tsai MW, Shih YF, Wei SH, Chou LW. Investigating the Effects of Peripheral Electrical Stimulation on Corticomuscular Functional Connectivity Stroke Survivors. Top Stroke Rehabil. 2016;23:154-62. 
Lai SM, Studenski S, Duncan PW, Perera S. Persisting consequences of stroke measured by the Stroke Impact Scale. Stroke. 2002;33:1840-4.

Langhorne P, Coupar F, Pollock A. Motor recovery after stroke: a systematic review. Lancet Neurol. 2009;8:741-54.

Larsen LH, Jensen T, Christensen MS, Lundbye-Jensen J, Langberg H, Nielsen JB. Changes in corticospinal drive to spinal motoneurones following tablet-based practice of manual dexterity. Physiol Rep. 2016;4.

Lawrence DG, Kuypers HG. The functional organization of the motor system in the monkey. I. The effects of bilateral pyramidal lesions. Brain. 1968;91:1-14.

Lemon RN. Descending pathways in motor control. Annu Rev Neurosci. 2008;31:195-218.

Lemon RN, Kirkwood PA, Maier MA, Nakajima K, Nathan P. Direct and indirect pathways for corticospinal control of upper limb motoneurons in the primate. Prog Brain Res. 2004;143:263-79. Maulden SA, Gassaway J, Horn SD, Smout RJ, DeJong G. Timing of initiation of rehabilitation after stroke. Arch Phys Med Rehabil. 2005;86:S34-s40.

Medical Research Council. Aids to the Examination of the Peripheral Nervous System. London: Bailliere Tindall; 1986.

Mima T, Toma K, Koshy B, Hallett M. Coherence Between Cortical and Muscular Activities After Subcortical Stroke. Stroke. 2001;32:2597-601.

Oldfield RC. The assessment and analysis of handedness: the Edinburgh inventory. Neuropsychologia. 1971;9:97-113.

Perez MA, Lundbye-Jensen J, Nielsen JB. Changes in corticospinal drive to spinal motoneurones following visuo-motor skill learning in humans. J Physiol. 2006;573:843-55.

Pollock A, Farmer SE, Brady MC, Langhorne P, Mead GE, Mehrholz J, et al. Interventions for improving upper limb function after stroke. Cochrane Database Syst Rev. 2014;(11):CD010820. Porter R, Lemon RN. Corticospinal function and voluntary movement. Oxford: Clarendon Press; 1993.

Rehme AK, Eickhoff SB, Rottschy C, Fink GR, Grefkes C. Activation likelihood estimation metaanalysis of motor-related neural activity after stroke. Neuroimage. 2012;59:2771-82.

Reyes A, Laine CM, Kutch JJ, Valero-Cuevas FJ. Beta Band Corticomuscular Drive Reflects Muscle Coordination Strategies. Front Comput Neurosci. 2017;11:17.

Rossiter HE, Eaves C, Davis E, Boudrias MH, Park CH, Farmer S, et al. Changes in the location of cortico-muscular coherence following stroke. Neuroimage Clin. 2013;2:50-5. 
Schulz R, Park CH, Boudrias MH, Gerloff C, Hummel FC, Ward NS. Assessing the integrity of corticospinal pathways from primary and secondary cortical motor areas after stroke. Stroke. 2012;43:2248-51.

Soteropoulos DS, Edgley SA, Baker SN. Lack of evidence for direct corticospinal contributions to control of the ipsilateral forelimb in monkey. J Neurosci. 2011;31:11208-19.

Soteropoulos DS, Williams ER, Baker SN. Cells in the monkey ponto-medullary reticular formation modulate their activity with slow finger movements. J Physiol. 2012;590:4011-27.

Stewart JC, Dewanjee P, Tran G, Quinlan EB, Dodakian L, McKenzie A, et al. Role of corpus callosum integrity in arm function differs based on motor severity after stroke. Neuroimage Clin. 2017;14:641-7.

Stinear CM, Barber PA, Smale PR, Coxon JP, Fleming MK, Byblow WD. Functional potential in chronic stroke patients depends on corticospinal tract integrity. Brain. 2007;130:170-80.

Strauss ES, E.M.S.; Spreen, O. A compendium of neuropsychological tests, administration, norms, and commentary. New York: Oxford University Press 2006.

Sunderland A, Tinson D, Bradley L, Hewer RL. Arm function after stroke. An evaluation of grip strength as a measure of recovery and a prognostic indicator. J Neurol Neurosurg Psychiatry. 1989;52:1267-72.

Tecchio F, Porcaro C, Zappasodi F, Pesenti A, Ercolani M, Rossini PM. Cortical short-term fatigue effects assessed via rhythmic brain-muscle coherence. Exp Brain Res. 2006;174:144-51.

Thomas CK, Butler JE, Zijdewind I. Patterns of pathological firing in human motor units. Adv Exp Med Biol. 2002;508:237-44.

van Asseldonk EH, Campfens SF, Verwer SJ, van Putten MJ, Stegeman DF. Reliability and agreement of intramuscular coherence in tibialis anterior muscle. PLoS One. 2014;9:e88428. Volz LJ, Sarfeld AS, Diekhoff S, Rehme AK, Pool EM, Eickhoff SB, et al. Motor cortex excitability and connectivity in chronic stroke: a multimodal model of functional reorganization. Brain Struct Funct. 2015;220:1093-107.

von Carlowitz-Ghori K, Bayraktaroglu Z, Hohlefeld FU, Losch F, Curio G, Nikulin VV. Corticomuscular coherence in acute and chronic stroke. Clin Neurophysiol. 2014;125:1182-91. Werhahn KJ, Conforto AB, Kadom N, Hallett M, Cohen LG. Contribution of the ipsilateral motor cortex to recovery after chronic stroke. Ann Neurol. 2003;54:464-72.

Witham CL, Riddle CN, Baker MR, Baker SN. Contributions of descending and ascending pathways to corticomuscular coherence in humans. J Physiol. 2011;589:3789-800. 
Xu J, Ejaz N, Hertler B, Branscheidt M, Widmer M, Faria AV, et al. Separable systems for recovery of finger strength and control after stroke. J Neurophysiol. 2017;118:1151-1163. doi: 10.1152/jn.00123.2017.

$\mathrm{Xu}$ J, Haith AM, Krakauer JW. Motor Control of the Hand Before and After Stroke. Clinical Systems Neuroscience Springer; 2015. p. 271-89.

Zaaimi B, Edgley SA, Soteropoulos DS, Baker SN. Changes in descending motor pathway connectivity after corticospinal tract lesion in macaque monkey. Brain. 2012;135:2277-89. 


\section{Legends}

Figure 1: A) Experiment setup. B) Raw EEG data from the contralateral sensorimotor cortex and rectified EMG recordings from the affected FDI are shown together with performance of one trial. The horizontal curly bracket illustrates the steady hold phase of which were used for the later calculation of coherence.

Figure 2: Bar graphs demonstrating changes in behavioral measurements for patients at T1 (red), T2 (light blue) and for controls (dark blue) from the affected (tested) hand in A) MVC, B) Pegboard test and C) The dynamic pinch task.

Figure 3: Data from one patient at $\mathrm{T} 1$ (red) and one control participant (dark blue) calculated from $2 \mathrm{~s}$ hold phase. The figure illustrate A) EEG power spectrum (contralateral sensorimotor cortex), B) the $\mathrm{EMG}_{\mathrm{FDI}}$ power spectrum, C) the coherence estimate and D) the cumulant density estimate.

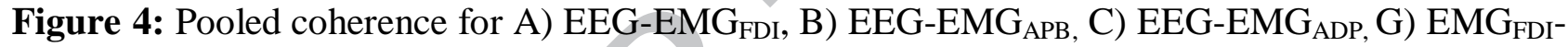
$\mathrm{EMG}_{\mathrm{APB}}$ and $\mathrm{H}$ ) $\mathrm{EMG}_{\mathrm{FDI}}-\mathrm{EMG}_{\mathrm{ADP}}$ for patients at $\mathrm{T} 1$ (red), $\mathrm{T} 2$ (light blue) and for controls (dark blue). D-F and I-J shows the $\chi^{2}$ extended test for differences of coherence estimates between respectively patients at T1 vs. T2 (light blue) and patients at T1 vs. controls (dark blue). The dashed horizontal lines in all plots denote the $95 \%$ confidence limits.

Figure 5: Individual amount of coherence (logarithm of cumulated sum) for A) EEG-EMG $\mathrm{FDI}_{1}, \mathrm{~B}$ ) EEG-EMG $\mathrm{APB}_{\mathrm{AP}}$ and C) $\mathrm{EEG}-\mathrm{EMG}_{\mathrm{ADP}}$, D) $\mathrm{EMG}_{\mathrm{FDI}}-\mathrm{EMG}_{\mathrm{APB}}$ and $\left.\mathrm{E}\right) \mathrm{EMG}_{\mathrm{FDI}}-\mathrm{EMG}_{\mathrm{ADP}}$ in the alpha band $(5-15 \mathrm{~Hz})$ and $\mathrm{F}-\mathrm{J})$ in the beta band $(15-30 \mathrm{~Hz})$ for patients at $\mathrm{T} 1$ and $\mathrm{T} 2$. Red lines represents mean of included patients.

Figure 6: Scalp plot of CMC from EEG-EMG $\mathrm{FDI}_{\text {in }}$ the beta band estimated for A) patients at T1, B) patients at T2 and C) controls. The small white circle illustrates the location of the electrodes used for analysis (C3/C4).

Table 1: Clinical information of patients 
$\mathrm{F}=$ female; $\mathrm{M}=$ male; Aff=affected; $*=$ dominant hand; $\mathrm{R}=$ right; $\mathrm{L}=\mathrm{left}$; MRC=Medical Research Council scale; MMSE=Mini Mental State Examination. Lesion location based on: $C T(3), \operatorname{MR}(\mathbf{5})$ and clinically diagnosed(7). 
Table 1

\begin{tabular}{|c|c|c|c|c|c|c|c|c|c|}
\hline Participant & Sex & Age, yr. & $\begin{array}{l}\text { Aff. } \\
\text { hand }\end{array}$ & $\begin{array}{l}\text { MRC } \\
\text { Aff. }\end{array}$ & MMSE & Lesion location & Additional radiological info & $\begin{array}{l}\text { Recor } \\
\text { T1 }\end{array}$ & $\begin{array}{l}\text { g day } \\
\text { T2 }\end{array}$ \\
\hline 1 & $\mathrm{~F}$ & 80 & $\mathrm{R}^{*}$ & $5-$ & 26 & L. Primary motor cortex & & 1 & 37 \\
\hline 2 & $\mathrm{M}$ & 49 & $\mathrm{R}$ & 4 & 25 & L. Corona radiata & & 8 & \\
\hline 3 & M & 56 & $\mathrm{R}^{*}$ & $4+$ & 28 & L. Subcortical motor tract & & 4 & 34 \\
\hline 4 & $M$ & 68 & $\mathrm{~L}$ & $5-$ & 28 & R. Subcortical motor tract & & 3 & 30 \\
\hline 5 & $\mathrm{M}$ & 57 & $\mathrm{R}^{*}$ & $4+$ & Missing & L. Primary motor cortex & $\begin{array}{l}\text { Small calcifications in } \\
\text { internal capsule bilaterally }\end{array}$ & 3 & 52 \\
\hline 6 & $\mathrm{M}$ & 31 & $\mathrm{R}^{*}$ & 4 & 30 & L. Corona radiata & & 6 & 55 \\
\hline 7 & $M$ & 45 & $\mathrm{~L}$ & 4 & 27 & R. Frontoparietal cortex & 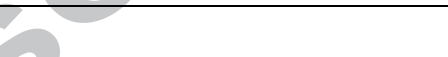 & 5 & 50 \\
\hline 8 & $\mathrm{M}$ & 86 & $\mathrm{~L}$ & $4+$ & 27 & R. Premotor area & & 6 & 34 \\
\hline 9 & $\mathrm{~F}$ & 56 & $\mathrm{R}^{*}$ & $5-$ & 28 & L. Insula + temporoparietal & & 2 & 36 \\
\hline 10 & $\mathrm{M}$ & 75 & $\mathrm{~L}$ & $4+$ & 23 & R. Pons & & 2 & \\
\hline 11 & $\mathrm{M}$ & 50 & $\mathrm{~L}$ & $4+$ & 29 & R. Corona radiata & Advanced leucoariosis & 4 & 36 \\
\hline 12 & M & 60 & $\mathrm{~L}$ & 4 & 28 & R. Deep perisylvanic & & 2 & 34 \\
\hline 13 & $\mathrm{M}$ & 49 & $\mathrm{R}^{*}$ & $4+$ & 28 & L. Primary motor cortex & $\begin{array}{l}\text { Seperate lesion semioval } \\
\text { center. }\end{array}$ & 1 & 34 \\
\hline 14 & M & 58 & $\mathrm{~L}$ & $5-$ & 26 & R. Premotor area & & 2 & 32 \\
\hline 15 & $\mathrm{M}$ & 60 & $\mathrm{R}^{*}$ & 4 & 24 & L. Pons & Intracranial metal object & 2 & 33 \\
\hline Mean (SD) & $2 \mathrm{~F}$ & $59(15)$ & $8 \mathrm{R}$ & & $27(2)$ & & & $3(2)$ & $38(8)$ \\
\hline
\end{tabular}


A)

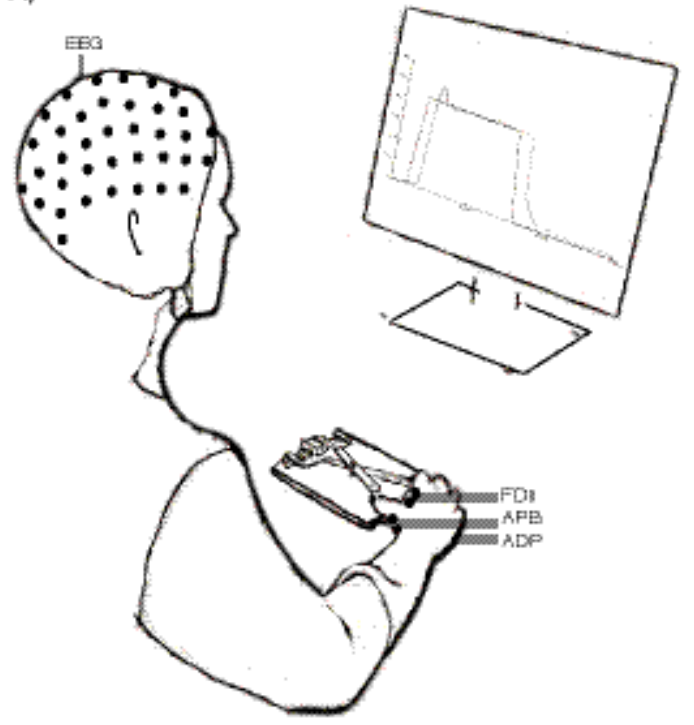

B)

EES

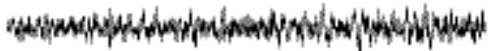

$\operatorname{limec}^{n \rho p}$

Finctified FDI EMAG

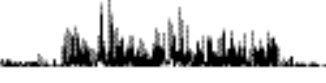

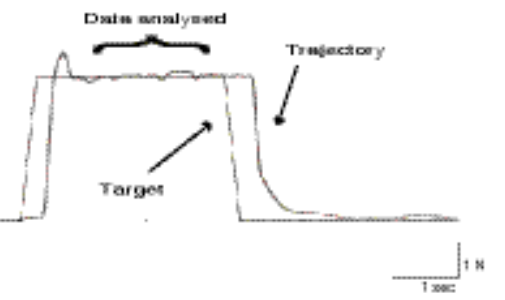



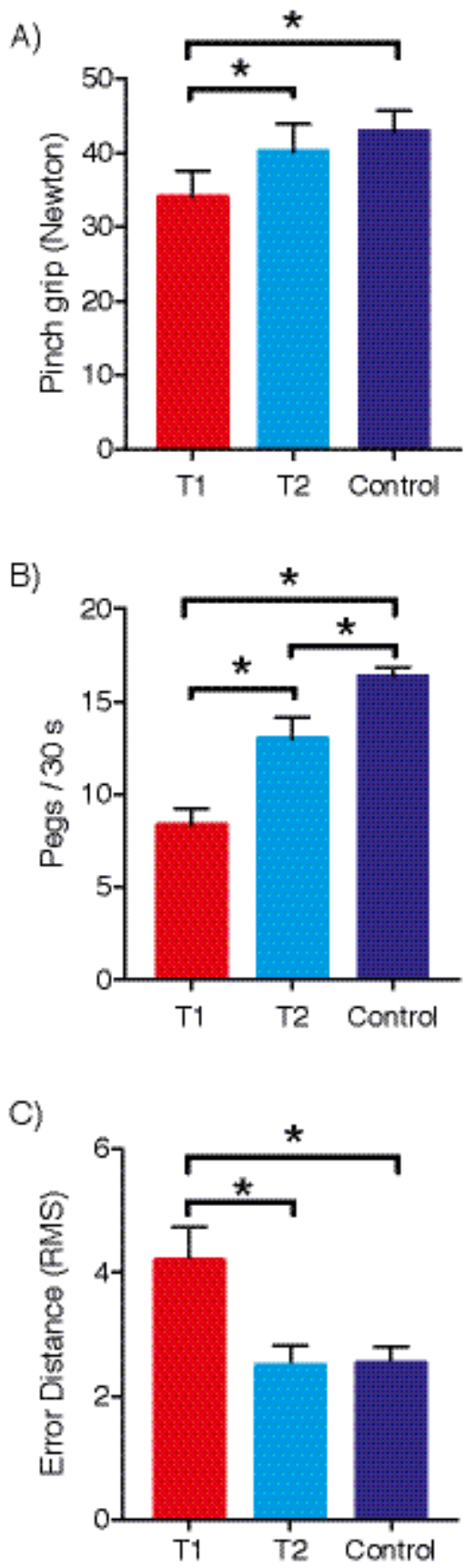

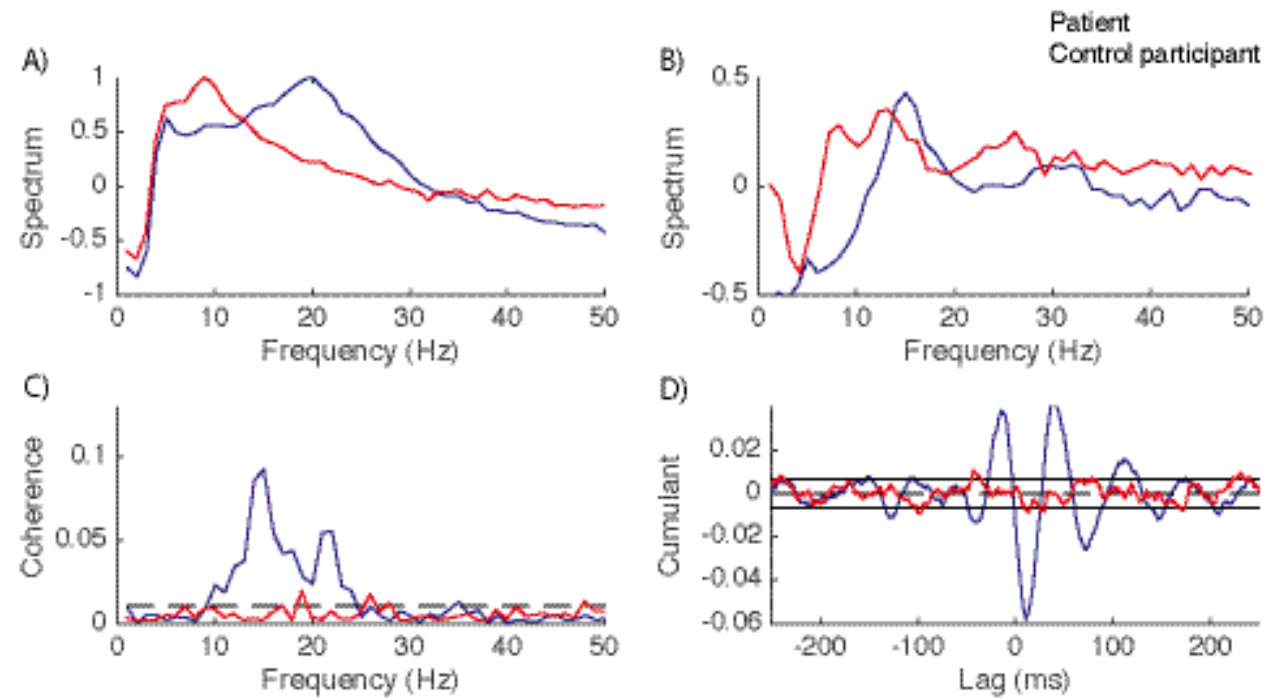


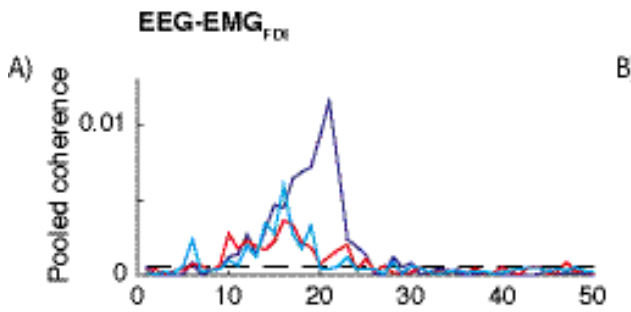

EEG-EMG

B)

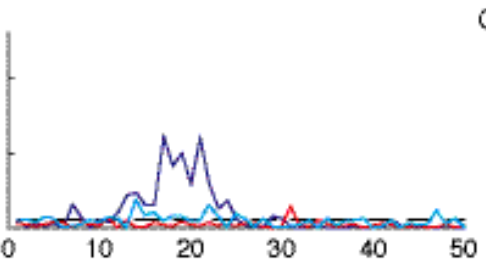

$E E G-E M G_{A D P}$

C)

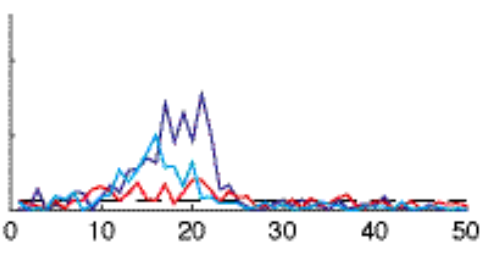

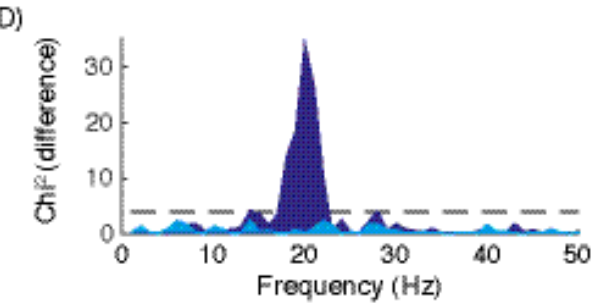
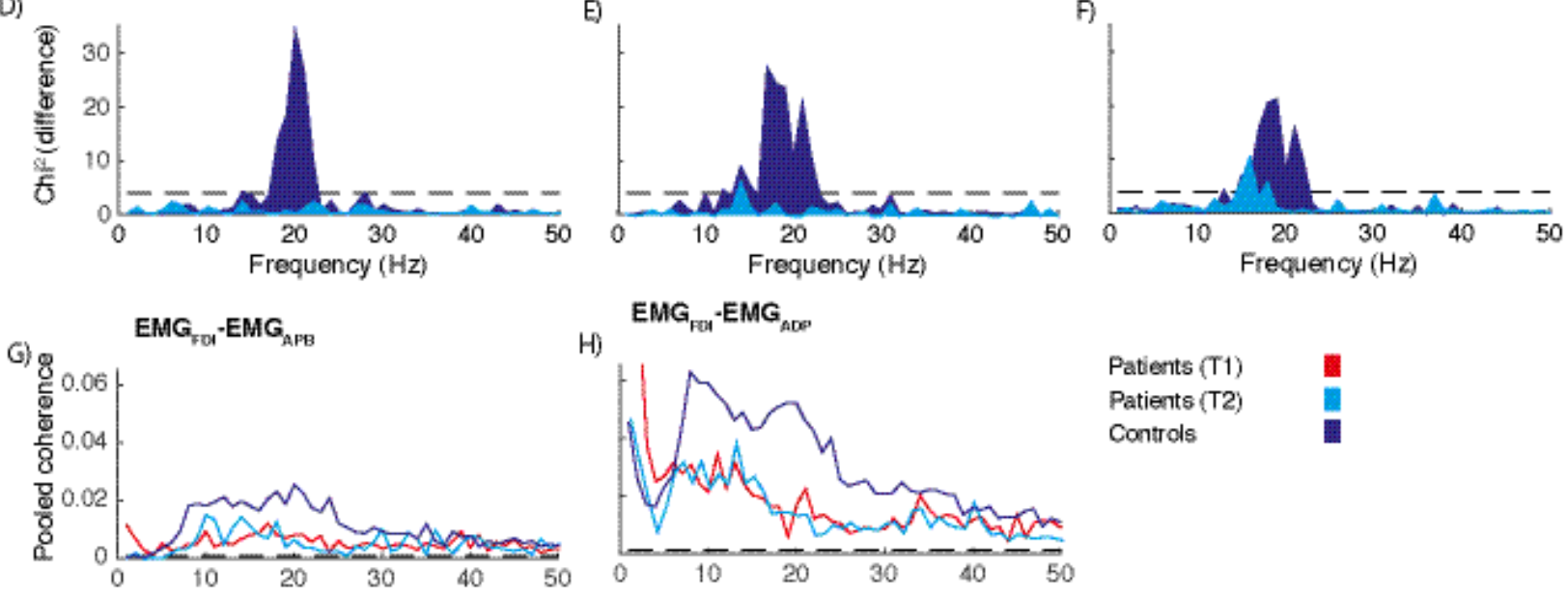
$\mathrm{EMG}_{\mathrm{Fa}}-\mathrm{EMG}_{\mathrm{ADE}}$
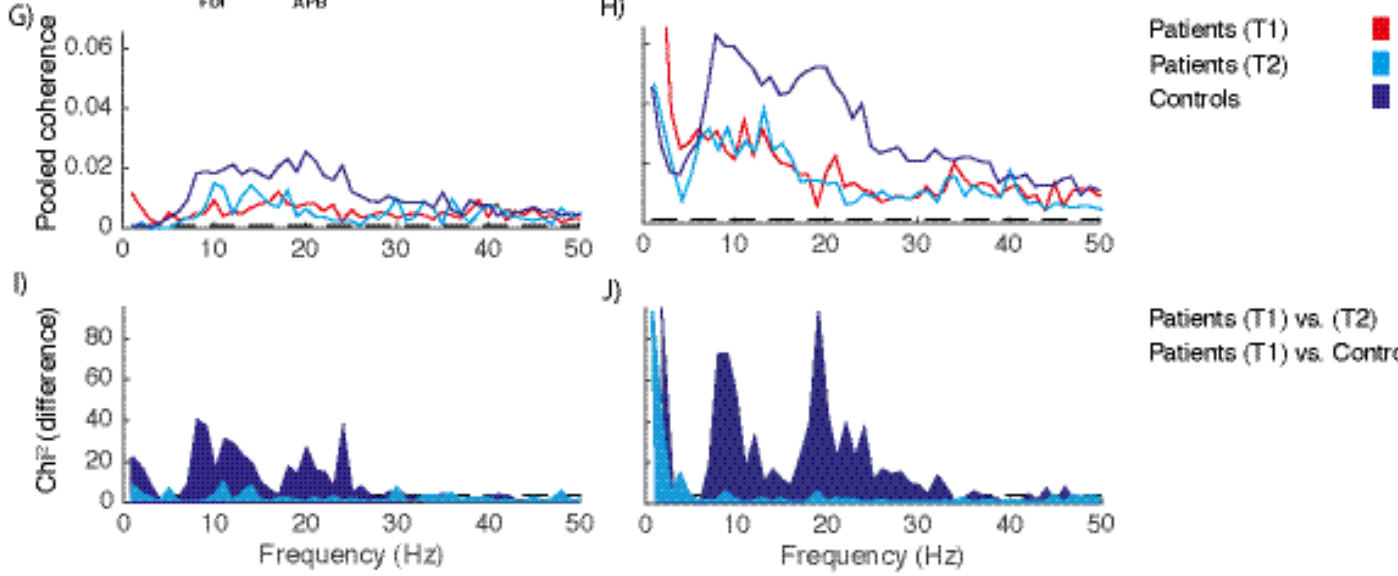

Controls

J)

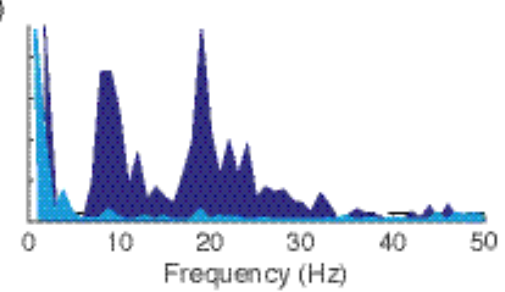

Patients (T1) va (T2)

Patients (T1) vs Controls 


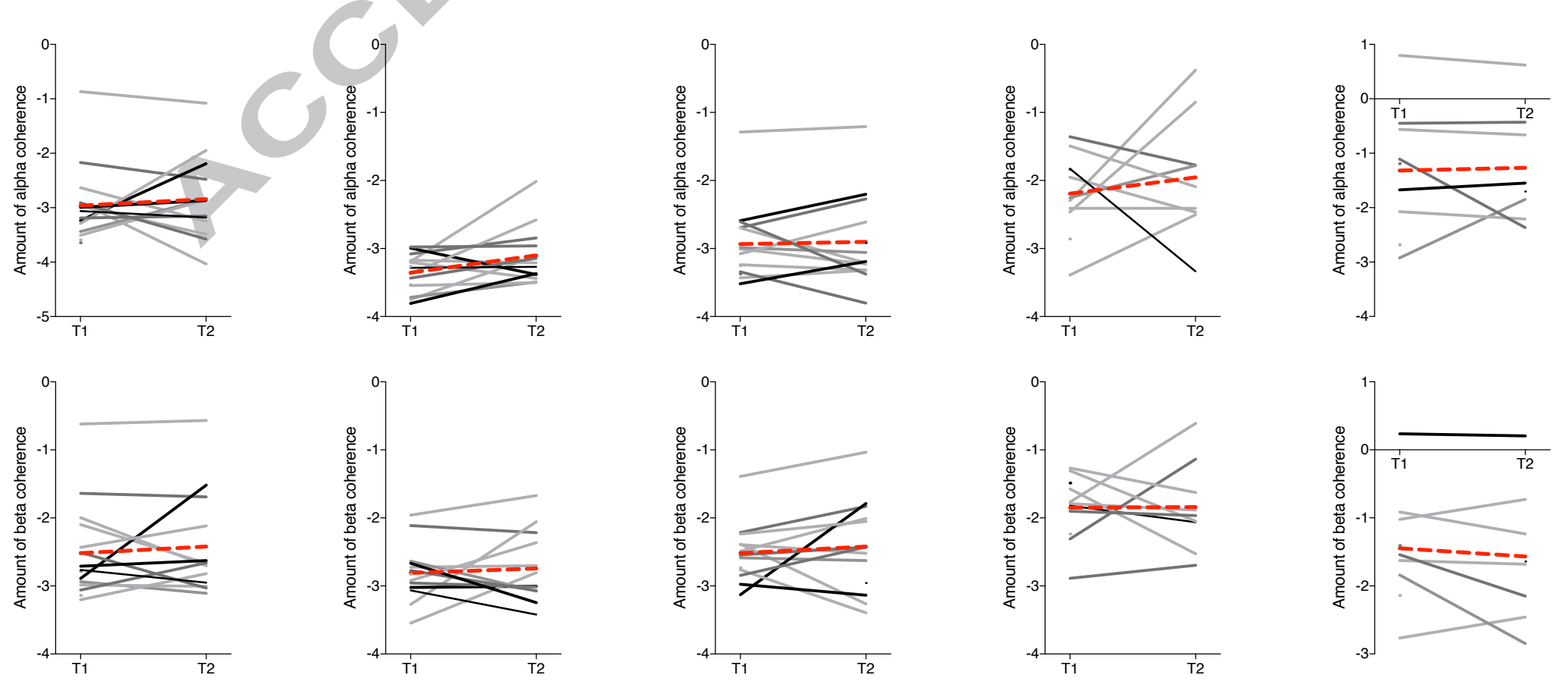




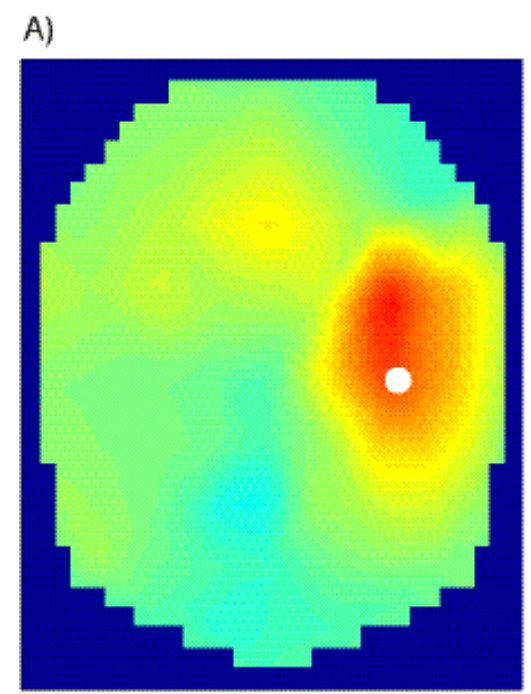

B)

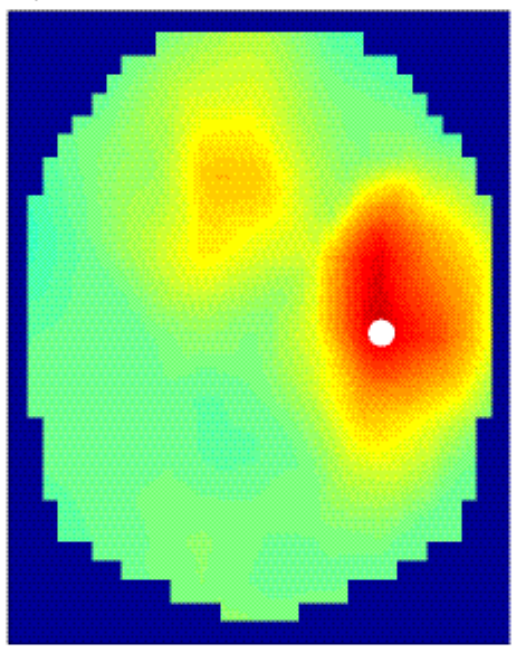

C)

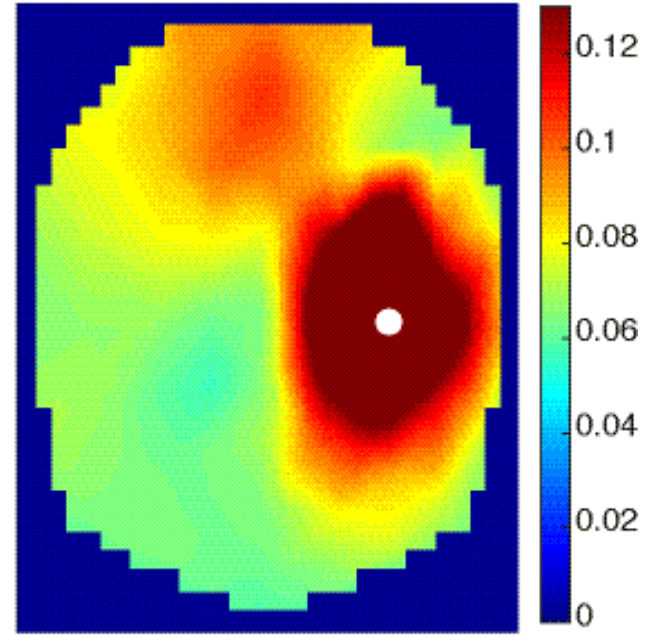

